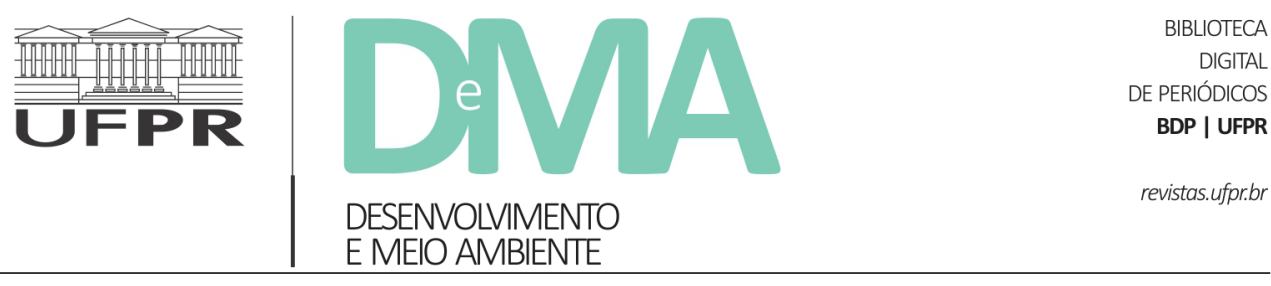

\title{
Apontamentos gerais sobre agronegócio e sindemia no Brasil
}

\section{General notes on agribussiness and syndemya in Brazil}

\author{
Leonardo MELGAREJO ${ }^{*}$, Acácio Zuniga LEITE² \\ ${ }^{1}$ Programa de Pós-Graduação em Agroecossistemas, Universidade Federal de Santa Catarina (UFSC), Florianópolis, SC, Brasil. \\ ${ }^{2}$ Programa de Pós-Graduação em Desenvolvimento Sustentável, Centro de Desenvolvimento Sustentável (CDS), Universidade de Brasília \\ (UnB), Brasília, DF, Brasil. \\ *E-mail de contato: melgarejo.leonardo@gmail.com
}

Artigo recebido em 30 de setembro de 2020, versão final aceita em 16 de março de 2021, publicado em 30 de junho de 2021.

RESUMO: $\quad$ O artigo contém uma reflexão exploratória sobre as contradições do modelo agroquímico no contexto atual das políticas de desenvolvimento rural no Brasil. Abordamos a teia de inter-relações envolvendo a proliferação de cultivos transgênicos, a flexibilização dos arranjos institucionais que limitam e controlam o uso de agrotóxicos, a expansão em ritmo acelerado dos desmatamentos e os atentados cada vez mais frequentes aos direitos fundamentais das populações tradicionais. Além disso, os impactos atuais e potenciais gerados por um novo ciclo de zoonoses com perfil sindêmico, ameaçando ao mesmo tempo a soberania nacional, os direitos humanos e a utilização prudente e equitativa do patrimônio natural e cultural do povo brasileiro, são ressaltados. Por fim, propomos uma nova maneira de pensar e gerir sistemas agroalimentares num cenário de agravamento acelerado da crise socioecológica global.

Palavras-chave: biotecnologia; agronegócio; transgênicos; agroecologia.

ABSTRACT: The article contains an exploratory analysis on agrochemical model contradictions in the current Brazilian rural development policies. We discuss the relation between proliferation of transgenic crops, changes in institutional arrangements that should limit and control pesticides use, rapid expansion of deforestation and increasingly attacks on traditional populations fundamental rights. In addition, current and potential impacts generated by a new cycle of zoonoses with syndemic profile are highlighted, threatening national sovereignty, human rights and prudent and equitable use of natural and cultural heritage of Brazilian people. Finally, we propose a new way of thinking and managing agri-food systems proposal to face the global socio-ecological crisis scenario.

Keywords: biotechnology; agribussiness; transgenic; agroecology. 


\section{Introdução}

Nas discussões em curso acerca da evolução do agronegócio no Brasil, seus aspectos positivos são geralmente colocados em primeiro plano. Apoiadas numa visão de curto prazo e alimentadas pelo boom da produção de commodities (Sauer \& Leite, 2012), essas análises concentram-se nas supostas vantagens econômicas comparativas da inserção do País na economia globalizada por meio de uma economia primário-exportadora (CNA, 2018; Cruvinel, 2009; Cadernos FGV Projetos, 2019; MAPA, 2019). Entretanto essas crenças vêm sendo contestadas por um número crescente de intérpretes que insistem na necessidade de uma avaliação mais rigorosa das múltiplas externalidades negativas geradas pela adoção desse modelo produtivo (Delgado, 2012; Domingues et al., 2014; Delgado \& Bergamasco, 2017; Pompeia, 2020). Como exemplos, podemos citar a contaminação das águas (Alonso et al., 2018), a erosão biocultural (Toledo \& Barrera-Bassols, 2015), a intensificação dos conflitos pela posse de áreas agricultáveis (Sassen, 2016), o aumento da concentração fundiária (Santos \& Glass, 2018) e dos desmatamentos (Domingues et al., 2014), além do comprometimento da segurança alimentar de amplos setores marginalizados da população e mesmo da soberania nacional (CONSEA, 2014; Santos \& Glass, 2018). Esta abordagem crítica associa também as ameaças à saúde individual e coletiva ao comprometimento acelerado dos sistemas de suporte da vida no planeta (Fernandes et al., 2013; Carneiro et al., 2015; UNCTAD, 2013; IAASTD, 2016; Hallmann et al., 2017; Bombardi,
2017; Sánchez-Bayo \& Wyckhuys, 2019; Acción por la Biodiversidad, 2020; WEF, 2020a; 2020b).

Mais recentemente, as complexas relações envolvendo a dinâmica de sistemas agroalimentares, as mudanças climáticas e as políticas de promoção da saúde vêm adquirindo uma projeção mundial, a exemplo da publicação do relatório da Comissão Lancet (Swinburn et al., 2019). Nesse documento, o cenário atual é caracterizado em termos de uma sindemia ${ }^{1}$ global de produção e consumo de alimentos envenenados, obesidade, subnutrição e intensificação de distúrbios climáticos. No tratamento da temática relacionada aos critérios de racionalidade pressupostos nos sistemas dominantes de produção agropecuária, emergem novas abordagens que desvelam o perfil interdependente das dimensões socioeconômica, sociocultural, sociopolítica e socioecológica. As evidências disponíveis tendem a confirmar que o modelo dominante de extrativismo agrário (McKay, 2017), inspirado na tradição das plantations (McKittrick, 2013), apoia-se em mecanismos que ameaçam o presente e o futuro da humanidade (Zanoni et al., 2011; UNEP, 2016; Fernandes, 2019; ACB, 2019; UNEP \& ILRI, 2020). Além de pressupor uma utilização intensiva de agrotóxicos e transgênicos, esse modelo é visto como um dos fatores determinantes da tendência de aquecimento global (UNEP, 2016) e da irrupção de novas zoonoses e pandemias - a exemplo da COVID-19 (UNEP, 2016; UNEP \& ILRI, 2020; WEF, 2020a; 2020b; Fiebrig et al., 2020).

A consolidação desse modelo produtivo atende a interesses específicos de grupos e corporações em detrimento do atendimento de necessidades básicas de povos e nações submetidos às coações impostas

\footnotetext{
${ }^{1}$ Quando a interação entre fatores se sobrepõe, acarretando danos maiores do que a simples soma dos danos causados isoladamente por cada fator.
} 
pela globalização neoliberal (Shiva, 2003; Santos \& Glass, 2018; ACB, 2019; Acción por la Biodiversidad, 2020; Shiva et al., 2020). Trata-se, de uma estratégia renovada de ingerência neocolonialista que substitui as ocupações militares convencionais (Mattis \& Hoffman, 2005; Korybko, 2018) por novas formas de controle de dinâmicas territorializadas de desenvolvimento rural excludente. No caso do Brasil, desde a época da destituição forçada da então presidente Dilma Rousseff, vêm se intensificando as evidências de ecocídio que acompanham o avanço acelerado dessa opção de dinamização do meio rural (FIAN et al., 2018). A edição do "Dia do fogo" em 2019, quando grileiros realizaram uma ação orquestrada para incendiar diversas áreas de floresta na região amazônica, exprime de forma exemplar uma tendência destrutiva que está se disseminando não só pelo território nacional como por outros países latino-americanos (Acción por la Biodiversidad, 2020; Zanoni et al., 2011; Castilho, 2012; Carneiro et al., 2015; Bombardi, 2017; Barcelos, 2018; Souza \& Folgado, 2019).

Neste artigo, apresentamos uma caracterização sintética dos impactos decorrentes dos cultivos geneticamente modificados e agrotóxicos associados (Ferment et al., 2015; Carneiro et al., 2015; Almeida et al., 2017; Bombardi, 2017), bem como de suas relações com os retrocessos que vêm sendo efetivados nos arranjos institucionais correspondentes (Folgado, 2017; Souza \& Folgado, 2019; Acción por la Biodiversidad, 2020). Na segunda parte, abordamos as perspectivas de surgimento de novas crises zoonóticas de corte pandêmico, relacionadas ao agravamento da crise global (UNEP, 2016). $\mathrm{Na}$ terceira, colocamos em discussão a necessidade de avançarmos na formulação de políticas de suporte a novos métodos de produção agropecuária inspira- dos no Princípio de Precaução (Myhr \& Traavick, 2002; Ferment et al., 2015). Argumentamos que deveriam ser priorizadas novas modalidades de apropriação e uso dos recursos naturais comensuradas à promoção de resiliência agroecossistêmica - indo além das medidas de corte curativo que se tornaram hegemônicas e insuficientes.

\section{O agronegócio, a produção de alimentos e a transgenia}

Nas economias de mercado globalizadas, o modelo do agronegócio se autoimpõe, cada vez mais, como uma suposta condição indispensável de combate à insegurança alimentar (ABAG, 1993; CNA 2018). Esse modelo, que se baseia essencialmente em monocultivos de lavouras geneticamente modificadas, asseguraria - de acordo com seus defensores - expansão da produtividade, superação de problemas bióticos e abióticos, e redução no uso de agrotóxicos, ampliando mecanismos de proteção ao ambiente e à saúde (ISAAA, 2018). Essas premissas tem justificado a criação de novos arranjos institucionais que flexibilizam a regulamentação de danos socioecológicos e legitimam o uso de agrotóxicos e a expansão dos cultivos transgênicos em diversos países latino-americanos (Fernandes et al., 2013; Acción por la Biodiversidad, 2020). Como exemplos brasileiros, podemos citar a alteração do Código Florestal em 2012; alterações na legislação fundiária em 2016 (Sauer \& Leite, 2017); em 2017, a conversão de multas ambientais; em 2018, renegociações de dívidas do agronegócio (Leite et al., 2018) e a autorização da mistura de agrotóxicos no tanque pelo MAPA; já em 2019, a reclassificação toxicológica dos agrotóxicos pela ANVISA, a elimi- 
nação do prazo para adesão ao Cadastro Ambiental Rural e a ampliação do armamento rural, além de vários atos de fala e a inércia institucional contra povos e comunidades tradicionais e em estímulo ao desmatamento e à impunidade (Sauer et al., 2020).

Entretanto, nas últimas décadas, o acúmulo de evidências empíricas compartilhadas por estudos independentes exige uma reavaliação dos pressupostos que sustentam esse modelo. Tais evidências contrariam a hipótese do uso seguro das tecnologias químicas e genéticas do agronegócio (Myhr \& Traavick, 2002; Benbrook, 2009; Gurian-Sherman, 2009; Tabashnik et al., 2013; Carneiro et al., 2015; Hilbeck et al., 2015; Alonso et al., 2018; Ribeiro, 2018; Lara et al., 2019).

Paralelamente, constata-se que a produção de alimentos em escala global pode ser suficiente para atender às necessidades básicas das populações - mesmo levando-se em conta as curvas de crescimento da população mundial - e que o modelo de agronegócio industrial não seria tão relacionado, como dizem seus defensores, à alimentação humana. As pesquisas realizadas no campo das estratégias alternativas de desenvolvimento socioeconômico têm mostrado que o avanço da obesidade e os condicionantes estruturais da persistência dos bolsões de pobreza nos cinco continentes decorrem sobretudo dos desequilíbrios na distribuição equitativa das riquezas, da fragilização crescente dos sistemas produtivos de base comunitária, da especulação no mercado de alimentos e da homogeneização dos padrões de consumo (Graziano da Silva, 2019).

Estima-se que atualmente cerca de 1,3 bilhões de toneladas de alimentos são desperdiçados, um volume considerado suficiente para alimentar mais de dois bilhões de pessoas (FAO, 2019; FAO et al., 2020). Essas perdas representam a terceira maior fonte emissora de gases de efeito estufa - num nível próximo do que já foi alcançado pelas economias da China e dos Estados Unidos. Além disso, estima-se que cerca de $38 \%$ da energia e $30 \%$ de terras agricultáveis consumidos pelo sistema alimentar global são direcionados para a geração dos desperdícios mencionados. Tudo isso já poderia justificar a necessidade imperativa de uma mudança drástica de rumos, visando reduzir as pressões sobre os sistemas de suporte da vida na ecosfera, como vem sendo proclamado pela ONU desde a década passada (IAASTD, 2008). Essas circunstâncias tornam-se ainda mais alarmantes se levarmos em conta as complexas interrelações recursivas envolvendo o aquecimento global, a irrupção de novas pandemias e a erosão da biossociodiversidade do planeta.

Ademais, já se tornou um lugar comum reconhecer que a ênfase colocada no cultivo de espécies geneticamente modificadas extrapola amplamente o domínio das políticas setoriais de produção de alimentos para a espécie humana. Ao contrário, as evidências disponíveis indicam fortes interfaces com as demandas crescentes de geração de matérias primas utilizadas na produção de rações, biocombustíveis, energia e fibras, deslocando áreas destinadas à produção de comida (Santos \& Glass, 2018; Acción por la Biodiversidad, 2020). Destaca-se que a estratégia produtiva baseada no cultivo de transgênicos extrapola as agroholdings e os grandes detentores de terra, espraiando-se para frações da agricultura familiar num processo de adaptação não autônoma e tentativa de participação em eventuais oportunidades econômicas. Nesses termos, a agricultura industrial fundamentada em cultivos transgênicos estaria associada tanto à consolidação de um círculo vicioso de expansão do uso de agrotóxicos quanto ao fomento de crimes ambientais e ao 
comprometimento dos mecanismos de democracia participativa (Santos \& Glass, 2018; Souza \& Folgado, 2019; Acción por la Biodiversidad, 2020).

Ainda segundo os relatórios divulgados pela FAO, a generalização desse modelo dominante de produção e consumo de alimentos afigura-se não só inviável em termos estratégicos, mas também já tendo alcançado um ponto-limite que ameaça a integridade da teia de inter-relações envolvendo a variedade de organismos vivos, os sistemas agroalimentares e os serviços ecossistêmicos indispensáveis ao florescimento da vida no planeta (FAO, 2019; FAO et al., 2020). Em números conhecidos, das cerca de 6 mil espécies de plantas cultivadas para alimentação, atualmente menos de 200 contribuem substancialmente para a produção global de alimentos e, destas, apenas nove respondem por $66 \%$ da produção agrícola total (FAO, 2019). Mais grave ainda é o fato de que, dentre elas, somente as lavouras de soja e milho podem ser consideradas itens alimentares relevantes, dentre todas as culturas incorporadas ao agronegócio apoiado na transgenia. No caso do Brasil, estima-se que 50,2 milhões de hectares estão sendo cultivados com variedades transgênicas (ISAAA, 2018).

As lavouras de milho e soja, geneticamente modificados por transgenia e cultivadas essencialmente em apenas cinco países, de forma alguma poderiam atender às crescentes necessidades alimentares do conjunto da população. Ademais, as modificações genéticas em questão permitem, tão somente, tolerância a herbicidas (Tecnologia $\mathrm{TH}$ ), produção de toxinas indutoras de resistência a insetos (Tecnologia RI), ou combinação de ambas as características (TH/RI) (Ferment et al., 2015; Fernandes, 2019). Outras formas de alteração genética, como a tolerância à seca e à salinidade e a resistência a fungos, viroses e bacterioses, são até aqui residuais ou fictícias (Gurian-Sherman, 2009; Ferment et al., 2015; Melgarejo, 2018).

Merece também atenção o fato de que a oligopolização do mercado dessas sementes não permite ilusões de soberania para os países comprometidos com seu cultivo. A prática de vendas antecipadas em mercados futuros para as commodities agrícolas gera responsabilidades internacionais que literalmente obrigam as nações subalternas, delas dependentes, a negociar em condições de inferioridade com as transnacionais detentoras das patentes envolvidas para garantir o acesso às sementes. Essa situação explica também o poder dos lobbies associados ao agronegócio, atuantes com os poderes constitucionais e em agências públicas comprometidas com áreas-chave de interesse das transnacionais do ramo (Barcelos, 2018; Acción por la Biodiversidad, 2020).

Essa associação entre as lavouras transgênicas e tecnologias voltadas ao controle de plantas (Tecnologia $\mathrm{TH}$ ) e insetos (Tecnologia RI), considerados indesejáveis, demonstra os estreitos vínculos entre as empresas produtoras daquelas sementes e dos agrotóxicos associados, dado que apenas um pequeno grupo de corporações transnacionais controla ambos os mercados em escala global. Em termos operacionais, o uso dos mesmos agrotóxicos, por safras sucessivas, nos mesmos ambientes, determina o surgimento de mutações de plantas e insetos supostamente controláveis pelas tecnológicas TH e RI. Essas mutações levam à emergência de populações resistentes àqueles agroquímicos e toxinas, demandando a utilização cada vez mais intensiva de agrotóxicos. Dessa forma, viabilizam a demanda de mercado para novas gerações de plantas transgênicas, envolvendo outros princípios 
ativos e novas combinações de toxinas (Melgarejo, 2018). Em outras palavras, o mercado de sementes transgênicas amplia o uso de agrotóxicos, levando à necessidade de novas gerações daquelas tecnologias, num círculo vicioso que beneficia os detentores das patentes e seus associados a montante e a jusante dos sistemas de produção agropecuária.

Em consequência desse mecanismo de resistência natural e dado que as modificações genéticas induzidas por transgenia não afetam diretamente os ganhos de produtividade, os agricultores se veem às voltas com custos operacionais que aumentam de forma desproporcional, comparativamente às receitas, e num contexto agravado por preços de mercado decrescentes (Melgarejo, 2018). Isso obriga os produtores a expandir suas áreas de cultivo visando resguardar suas margens de rentabilidade. Almeida et al. (2017) ilustram esse ponto mostrando de que maneira as lavouras transgênicas brasileiras vêm exigindo o aporte de volumes crescentes de agrotóxicos, a custos adicionais por tonelada de grãos colhidos na tentativa de simplificação do processo produtivo. Tornam-se, assim, evidentes as implicações negativas do ponto de vista da preservação da saúde dos habitantes e da resiliência dos ecossistemas e biomas. Essa situação já havia sido observada por Benbrook (2009) em suas pesquisas sobre a dinâmica do sistema agroalimentar em vigor nos Estados Unidos. Destaque-se que os ganhos de rendimento são de ordem multigênica, não se devendo à manipulação dos poucos fatores envolvidos nas tecnologias TH e RI utilizadas (Ferment et al., 2015; Melgarejo, 2018).

Em consequência, o modelo agrícola apoiado nas lavouras transgênicas pode ser um vetor relevante no processo de agravamento acelerado da crise socioecológica planetária. As evidências disponíveis já permitem que organizações internacionais recomendem alterações nos sistemas hegemônicos de produção e consumo, mobilizando para tanto não só o aprendizado que vem sendo obtido com sistemas alternativos de base agroecológica (UNCTAD, 2013; IAASTD, 2008), mas também com a gestão de bancos de sementes e de mosaicos de áreas protegidas - dentre outras formas de bioconservação genética (FAO, 2019; UNEP \& ILRI, 2020). Não surpreende assim que, para além dos movimentos camponeses em todo o mundo, o próprio Fórum Econômico Mundial apresente dados e recomendações similares, como veremos mais adiante (WEF, 2020a; 2020b).

\section{O agronegócio no contexto dos desequilíbrios ecossistêmicos e das novas pandemias emergentes}

Contrariando os sinais de alerta emitidos por diversas agências internacionais, bem como as reivindicações de movimentos populares do campo, o agronegócio tornou-se um dos pilares do imaginário desenvolvimentista que se consolidou no Brasil. As repercussões práticas desse processo podem ser observadas em dinâmicas destrutivas emblemáticas ao longo do território nacional, como é o caso do megaprojeto de incorporação da região do MATOPIBA $^{2}$ ao mercado internacional de soja. Trata-se de um território que corresponde aproximadamente à superfície da Itália e da Alemanha, onde existem 781 assentamentos de reforma agrária, 36 territórios

\footnotetext{
${ }^{2}$ Acrônimo formado com as iniciais dos estados do Maranhão, Tocantins, Piauí e Bahia, a região contempla 337 municípios.
} 
indígenas e 46 unidades de conservação ambiental. Nele, pretende-se adotar o cultivo extensivo de soja transgênica apoiado por recursos governamentais e privados, internos e externos, dispondo para tanto de infraestrutura de armazenamento, transporte e escoamento por terra e mar. A desconsideração das formas de vida existentes naqueles 73 milhões de hectares vem se somar aos múltiplos casos de ecocídio que acompanham essa linha de expansão do agronegócio brasileiro (FIAN et al., 2018).

No período de 1985 e 2018, a vegetação natural das áreas de fronteira agrícola no Brasil foram reduzidas em 89 milhões de hectares. Ao mesmo tempo, a área afetada pela agropecuária cresceu em 86 milhões de hectares (Mapbiomas, 2019). Uma fração importante da agricultura familiar mantém sistemas agrícolas tradicionais como fronteira agrobiodiversa nesses territórios (Eloy et al., 2020). Tais sistemas operam na contramão da agenda adotada pelo governo federal, segundo a qual só existe um modelo viável de produção e consumo de alimentos no Brasil (Sauer et al., 2020).

A trajetória do agronegócio em áreas consideradas ricas em biossociodiversidade caminha na contramão da Declaração das Nações Unidas sobre os Direitos dos Camponeses e das Camponesas, que compreende o acesso à terra e a diversidade biológica como direitos humanos, e acompanha a tendência de agravamento da crise socioecológica global. Além disso, responde ainda pelo surgimento de novas e surpreendentes modalidades de zoonoses - a exemplo da COVID-19 (UNEP \& ILRI, 2020). Dito de outra forma, no conjunto das externalidades negativas resultantes dessas práticas, emerge o fantasma de novos surtos de pandemias com efeitos sistêmicos cada vez mais devastadores. Ingressamos assim numa nova era de sindemias, na qual os riscos de consequências letais acabam sendo maiores para as populações mais pobres, que residem em torno dos remanescentes florestais ou em condições precárias em termos de saneamento básico.

Vale a pena salientar que a irrupção da nova pandemia no início de 2020 obedeceu a uma dinâmica já bem conhecida dos especialistas em epidemiologia. Tipos desconhecidos de vírus migram de animais selvagens para animais domésticos e seres humanos em função de desequilíbrios ecossistêmicos. A ciência atualmente aceita que a frequente emergência e mesmo a superposição de avanço das zoonoses associam-se à uma nova era das extinções (Barnosky et al., 2011; Naeem et al., 2012). A destruição de habitats provoca a migração de novas configurações de doenças antes contidas em nichos ecológicos prístinos, ainda não ou pouco antropizados. A destruição de nichos ecológicos elimina seres que ali convivem, em equilíbrio dinâmico, com doenças que lhes são próprias. $\mathrm{Na}$ ausência de hospedeiros selvagens, fungos, vírus e bactérias, que com eles interagem, são induzidos a buscar outras alternativas de subsistência. A proximidade, as deficiências nutricionais, as condições insalubres e o estresse, entre outras fragilidades, fazem de humanos e das criações de animais cativos para consumo de proteína animal as opções naturais para os patógenos. Assim, por meio de mutações ou simples acesso a novos hospedeiros, inabilitados ao convívio com tais enfermidades, os patógenos se adaptam a novos contextos. $\mathrm{Na}$ ausência de defesas naturais, eles se multiplicam e ampliam a sintomatologia - de forma geométrica até momento de descenso, quando os hospedeiros alcançam um equilíbrio imunológico ou se extinguem (UNEP, 2016). Estima-se que pelo menos 142 das principais doenças zoonóticas que afetam a humanidade 
originaram-se de animais silvestres em risco de extinção (Johnson et al., 2020).

Em síntese, argumentamos que a expansão desse modelo predatório pressupõe necessariamente a formação de monocultivos de plantas transgênicas dependentes do uso crescente de agrotóxicos. Trata-se de uma estratégia de desenvolvimento rural que se alimenta da erosão da biossociodiversidade e, ao mesmo tempo, compromete a saúde e a qualidade de vida das populações. Soma-se a isso a constatação de que as colheitas são utilizadas, em grande parte, como insumos de uma engrenagem contraprodutiva que conecta a megaindústria agropecuária à irrupção de pandemias de alto poder disruptivo.

Por outro lado, as evidências disponíveis revelam ainda os impasses que cercam a lenta consolidação de um movimento de transição agroecológica consequente no Brasil. As narrativas difundidas pelos seus arautos vêm se impondo no imaginário coletivo. $\mathrm{O}$ poderoso arranjo político assim formado congrega entidades vinculadas aos setores financeiro, midiático, alimentar e de distribuição - além daqueles diretamente relacionados à produção agropecuária em amplo sentido. As campanhas publicitárias "sou agro" e "o agro é pop", por exemplo, são transmitidas em meios de comunicação de massa para dar sustentação ideológica ao pacto de economia política do agronegócio e enfraquecer o potencial de construção democrática de uma agenda socioecológica compatível com um novo estilo de desenvolvimento (Pompeia, 2020).

$\mathrm{Na}$ interpretação de Vandana Shiva, pesquisadora e ativista indiana, na guerra em curso pela expansão ilimitada do agronegócio, certos mecanismos de comunicação estariam mantendo as populações atreladas a processos alienantes de monocultura das mentes, em que o espírito crítico pode chegar a ser até mesmo criminalizado (Shiva, 2003). Na sua opinião, que converge com a de muitos analistas, a ênfase concedida à aplicação de novos avanços no campo da engenharia genética não rompe com a lógica contraprodutiva subjacente aos sistemas agroalimentares que se tornaram hegemônicos - sobretudo na América Latina e no Continente Africano. Em outras palavras, os problemas decorrentes do avanço da primeira geração de produtos da engenharia genética não poderiam ser superados com a simples transição da transgenia (transferência e interação de genes provenientes de outros organismos) para a cisgenia (desativação, alteração ou potencialização na expressão de genes já existentes nos organismos) e outras formas de edição gênica. Os críticos do modelo descartam também a hipótese de que a manutenção da mesma política, ajustada a partir da mobilização de novas tecnologias, poderia gerar avanços efetivos ou estaria à altura dos complexos desafios colocados pelo atual cenário geopolítico. Além disso, diante do acúmulo de evidências contrárias, é crucial considerar as implicações éticas, morais, políticas e de saúde pública envolvidas (Ferment et al., 2015; Sousa \& Folgado, 2019; Gurgel et al., 2019; Acción por la biodiversidad, 2020). Nesse sentido, estrategistas globais buscam alternativas para prevenir novas crises, fortalecer sistemas imunológicos (Weitz et al., 2011) ou para romper as cadeias de transmissão, caso as pandemias surjam (UNEP \& ILRI, 2020). 


\section{Em busca de alternativas}

Diante das incertezas que marcam a perspectiva de um novo ciclo de zoonoses de virulência crescente, o debate internacional vem sendo enriquecido com novas abordagens que sugerem transformações paradigmáticas nos atuais padrões de alimentação, consumo e relacionamento com os ecossistemas e habitats. Nesse sentido, Dobson et al. (2020) apontam os limites das medidas de caráter reativo e reivindicam a experimentação com ações preventivas, comprovadamente mais econômicas, mais eficazes e menos traumatizantes. Os autores estimam que o custo global (no caso de ações capazes de prevenir por dez anos os danos econômicos decorrentes da atual pandemia) não superaria $2 \%$ dos prejuízos relacionados à gestão da COVID-19. Em escala global, as medidas preventivas alcançariam US\$ 31 bilhões, dos quais deveriam ser descontados cerca de US\$ 17 bilhões correspondentes a benefícios decorrentes da redução das emissões de carbono, com impactos sobre o aquecimento global.

Nesse debate, vêm se disseminando também várias linhas de argumentação que mobilizam uma crítica renovada das evoluções do capitalismo corporativo globalizado. Seus intérpretes colocam em primeiro plano, em contraste com as contradições supostamente inexoráveis do atual sistema agroalimentar, o potencial da agricultura familiar na construção de um novo projeto de sociedade de corte pós-pandêmico (Ploeg, 2020; Altieri \& Nicholls, 2020). Nos diagnósticos compartilhados por membros da Via Campesina - organização internacional composta por movimentos sociais de camponeses em todos os continentes -, podemos encontrar evidências suplementares dos impactos destrutivos da regulação socioeconômica baseada na lógica dos mercados competitivos globalizados - sobretudo no que diz respeito às implicações para o futuro de zonas rurais (Mpofu, 2020).

Da mesma forma, ao longo das últimas décadas, muitas agências internacionais vêm insistindo na necessidade de revermos os impasses que estão limitando as experimentações com novas formas de regulação dos processos de produção e consumo de bens e serviços. Segundo o relatório mais recente oriundo do Fórum Econômico Mundial (WEF, 2020b), se mantida no ritmo atual de agravamento da crise global, a curva (aparente) de prosperidade já alcançada de algumas regiões, mesmo no âmbito da economia internacional, passa a ser vista de outro ângulo. Torna-se uma miragem no deserto. Dentre os principais setores responsáveis pelo agravamento da tendência de erosão mais ou menos irreversível da biossociodiversidade, destacam-se as modalidades dominantes de apropriação e uso da terra e a generalização do paradigma agroquímico. Ainda segundo o mesmo relatório, com investimentos da ordem de US\$ 2,7 trilhões ao ano, seria possível redirecionar-até 2030 - as atividades produtivas e de consumo responsáveis pela extinção potencial de $79 \%$ das espécies ameaçadas, gerando 395 milhões de empregos e retornos estimados em US\$ 10,1 trilhões ao ano.

Os investimentos em questão seriam irrelevantes, conforme os analistas do WEF, se comparados com os estímulos de US\$2,2 trilhões anunciados em março de 2020, em resposta aos impactos causados pela irrupção da COVID-19 (WEF, 2020b). Em contraste, as entidades envolvidas na promoção do agronegócio no Brasil vêm construindo suas agendas estratégicas pleiteando a anistia de casos de desmatamento ilegal e grilagem de terras, além da 
flexibilização do licenciamento ambiental, da defesa de isenção tributária (inclusive sobre os agrotóxi$\cos$ ), e de redução do escopo de direitos trabalhistas já conquistados - dentre outras medidas regressivas (Leite et al., 2019). Parece-nos assim evidente que as limitações na busca de soluções alternativas são de natureza essencialmente política ${ }^{3}$.

\section{Considerações finais}

A corrida em escala global por terras agricultáveis, a expansão do sistema agroalimentar tecnocrático-corporativo e a defesa da necessidade de cultivos mobilizando moléculas de alto impacto contaminante convivem atualmente atrelados a uma nova fase de evolução do capitalismo. Essa combinação de elementos descortina novos e complexos desafios para os próximos tempos.

A perspectiva de um enfrentamento consequente da crise socioecológica planetária depende, a nosso ver, de uma mudança drástica de perspectiva estratégica ainda carente de legitimidade no imaginário dominante. Mas já dispomos de um amplo leque de experiências bem sucedidas e dotadas de efeito multiplicador. Propostas viáveis em termos tecnológicos de novos sistemas de produção e consumo localmente adaptados estão disponíveis e podem ser mobilizadas por agentes de mudança portadores de um novo princípio de racionalidade social ampliada, apoiada no aprendizado de proces- sos ecológicos historicamente construídos. A título de exemplo, considere-se o caso do arroz orgânico em assentamentos de reforma agrária no Rio Grande do Sul, exposto por Martins (2019), bem como as recomendações contidas em vários relatos de experiências acumuladas (Altieri \& Nicholls, 1999; IAASTD, 2008; Pinheiro Machado \& Pinheiro Machado Filho, 2014; PNUMA, 2017; FAO, 2018).

Todas essas iniciativas partem de uma mesma premissa. A saúde dos solos e a saúde das águas são essenciais para a manutenção de ecossistemas saudáveis. O enfrentamento consistente das sindemias que alimentam o aquecimento global e ameaçam a resiliência dos sistemas de suporte da vida e, por implicação, o futuro da civilização humana, exigem de forma imperativa a superação das práticas hegemônicas de promoção do agronegócio. Em última instância, trata-se de romper com as expectativas de generalização de modos de vida incompatíveis com a preservação das condições essenciais de habitabilidade em nossa "casa comum" (Papa Francisco, 2015). Seguindo essa trilha, talvez possamos superar a colonização epistêmica que nos ofusca e, ao mesmo tempo, recuperar o espaço reservado ao Brasil no contexto das nações.

\section{Referências}

ABAG - Associação Brasileira do Agronegócio. Segurança alimentar: uma abordagem de Agribusiness. São Paulo:

\footnotetext{
${ }^{3}$ A própria permanência no cargo e a constante validação das posturas do Ministro do Meio Ambiente, o ruralista e ex-diretor da Sociedade Rural Brasileira, Ricardo Salles, é emblemática para ilustrar o atual contexto de aceleração no desmonte das leis ambientais vigentes no país. Aqui, vale resgatar a recomendação de Salles ao presidente Bolsonaro durante uma reunião ministerial realizada em maio de 2020, que ganhou repercussão internacional. Nas palavras do ministro: "precisa ter um esforço nosso aqui enquanto estamos nesse momento de tranquilidade no aspecto de cobertura de imprensa, porque só fala de COVID e ir passando a boiada e mudando todo o regramento e simplificando normas. De IPHAN, de ministério da Agricultura, de ministério de Meio Ambiente, de ministério disso, de ministério daquilo. Agora é hora de unir esforços pra dar de baciada a simplificação regulam... é de regulatório que nós precisamos, em todos os aspectos" (Andrade \& Reis, 2020).
} 
ABAG, 1993.

Acción por la Biodiversidad. Atlas del agronegocio transgénico en el Cono Sur: monocultivos, resistencias y propuestas de los pueblos. Marcos Paz: Acción por la Biodiversidad, 2020. Disponível em: <http://www.biodiversidadla.org/ content/download/166026/1233910/version/1/file/Atlas+del+agronegocio+transg\%C3\%A9nico+en+el+Cono+Sur+-+Hoja+simple.pdf>. Acesso em: ago. 2020.

ACB - The African Centre for Biodiversity. Profiteering from health and ecological crises in Africa: The Target Malaria project and new risky GE technologies. Johannesburg: ACB, 2019. Disponível em: <https://www.acbio.org. $\mathrm{za} /$ sites/default/files/documents/202006/profiteering-health-and-ecological-crises-africathe-target-malaria-project-and-new-risky-ge_0.pdf>. Acesso em: set. 2020.

Almeida, V. E. S. de; Friedrich, K.; Tygel, A. F.; Melgarejo, L.; Carneiro, F. F. Uso de sementes geneticamente modificadas e agrotóxicos no Brasil: cultivando perigos. Ciência e Saúde Coletiva, 22(10), 3333-3339, 2017. doi: 10.1590/1413-812320172210.17112017

Alonso, L. L.; Demetrio, P. M.; Etchegoyen, M. A.; Marino, D. J. Glyphosate and atrazine in rainfall and soils in agroproductive areas of the pampas region in Argentina. Science of the Total Environment, 645, 89-96, 2018. doi: 10.1016/j. scitotenv.2018.07.134

Altieri, M.A.; Nicholls, C.I. Biodiversity, ecosystem function, and insect pest management in agricultural systems. New York, CRC Press, 1999.

Altieri, M.A.; Nicholls, C.I. Agroecology and the reconstruction of a post-COVID-19 agriculture. The Journal of Peasant Studies, 47(5), 881-898, 2020. doi: 10.1080/03066150.2020.1782891

Andrade, B. G. de; Reis, P. M. G. Laudo $n^{\circ}$ 1242/2020 INC/DITEC/PF. 2020. Disponível em: $<$ https://www.conjur. com.br/dl/degravacao-video-10.pdf>. Acesso em: set. 2020.

Barcelos, J. R. de O. Agrobiodiversidade Ameaçada: perversão do direito e zona de autarquia na Comissão Técnica Nacional de Biossegurança (CTNBio). São Paulo: Editora LiberArs, 2018.

Barnosky, A. D.; Matzke, N.; Tomiya, S.; Wogan, G. O.
U.; Swartz, B.; Quental, T. B.; Marshall, C.; McGuire, J. L.; Lindsey, E. L.; Maguire, K. C.; Mersey, B.; Ferrer, E. A. Has the Earth's sixth mass extinction already arrived? Nature, 471, 51-57, 2011. doi: 10.1038/nature09678

Benbrook, C. M. Impacts of Genetically Engineered Crops on Pesticide Use in the United States: the first thirteen years. Washington: The Organic Center, 2009. Disponível em: $<$ http://organic-center.org/reportfiles/GE13YearsReport. pdf $>$. Acesso em: set. 2020.

Bombardi, L. M. Geografia do uso de agrotóxicos no Brasil e conexões com a União Europeia. São Paulo: FFLCH-USP, 2017.

Cadernos FGV Projetos. Agronegócio, ano 14, n. 36, mar. 2019. Disponível em: <https://fgvprojetos.fgv.br/sites/ fgvprojetos.fgv.br/files/caderno_agronegocio_low.pdf $>$. Acesso em: set. 2020

Carneiro, F. F.; Augusto, L. G. S.; Rigotto, R. M.; Friedrich, K.; Búrigo, A. C. (Orgs.). Dossiê ABRASCO: um alerta sobre os impactos dos agrotóxicos na saúde. Rio de Janeiro: EPSJV; São Paulo: Expressão Popular; 2015.

Castilho, A. L. Partido da Terra: como os políticos conquistam o território brasileiro. São Paulo: Contexto, 2012.

CNA - Confederação Nacional da Agricultura. O Futuro é AGRO: 2018-2030. Brasília: CNA, 2018.

CONSEA - Conselho Nacional de Segurança Alimentar e Nutricional. Mesa de Controvérsias sobre Transgênicos: Relatório Final. Brasília: Presidência da República, 2014.

Cruvinel, P. E. Agronegócio e oportunidades para o desenvolvimento sustentável do Brasil. Documentos, 44, 9-19, 2009.

Delgado, G. C. Do capital financeiro na agricultura à economia do agronegócio: mudanças cíclicas em meio século. Porto Alegre, UFRGS, 2012.

Delgado, G. C.; Bergamasco, S. M. P. (Orgs.). Agricultura familiar brasileira: desafios e perspectivas de futuro. Brasília: Secretaria Especial de Agricultura Familiar e Desenvolvimento Agrário, 2017.

Dobson, A. P.; Pimm, S. L.; Hannah, L.; Kaufman, L.; Ahumada, J. A.; Ando, A. W.; Bernstein, A.; Busch, J.; Daszak , 
P.; Engelmann, J.; Kinnaird, M. F.; Li, B. V. ; Loch-Temzelides, T.; Lovejoy, T.; Nowak, K.; Roehrdanz, P. R. ; Vale, M. M. Ecology and economics for pandemic prevention. Science, 369(6502), 379-381, 2020. doi: 10.1126/science. abc3189

Domingues, M. S.; Bermann, C.; Manfredini, S. A produção de soja no Brasil e sua relação com o desmatamento na Amazônia. RPGeo, 1(1), 32-47, 2014. doi: 10.36026/ rpgeo.v1i1.2308

Eloy, L.; Souza, C.; Nascimento, D.; Nogueira, M. C. R.; Barreto Filho, H. T.; Bustamante, P.; Emperaire, L. Os sistemas agrícolas tradicionais nos interstícios da soja no Brasil: processos e limites da conservação da agrobiodiversidade. Confins, 45, 2020. doi: 10.4000/CONFINS.28182

FAO - Food and Agriculture Organization. Experiencias exitosas de politicas agroambientales en Brasil. Santiago: FAO, 2018.

FAO - Food and Agriculture Organization. El estado mundial de la agricultura y la alimentación: progresos en la lucha contra la pérdida y el desperdicio de alimentos. Roma: FAO, 2019. Disponível em: <http://www.fao.org/3/ ca6122es/ca6122es.pdf $>$. Acesso em: ago 2020.

FAO - Food and Agriculture Organization; IFAD - International Fund for Agricultural Development; UNICEF - United Nations International Children's Emergency; WFP - World Food Programme; WHO - World Health Organization. The State of Food Security and Nutrition in the World 2020: transforming food systems for affordable healthy diets. Rome: FAO, 2020. doi: 10.4060/ca9692en

Ferment, G.; Melgarejo, L.; Fernandes, G. B.; Ferraz, J. M. Lavouras transgenicas: riscos e incertezas: mais de 750 estudos desprezados pelos órgãos reguladores de OGM Brasília: MDA, 2015.

Fernandes, G. B. Novas biotecnologias, velhos agrotóxicos: um modelo insustentável que avança e pede alternativas urgentes. Rio de Janeiro: Fundação Heinrich Böll Brasil, 2019.

Fernandes, G. B.; Melgarejo, L.; Ferraz, J. M. G. Dez anos de cultivos transgênicos no Brasil: um balanço crítico. In: Anais VIII Congresso Brasileiro de Agroecologia, Porto Alegre, 2013.
FIAN - FoodFirst Information \& Action Network; Misereor; CPT - Comissão Pastoral da Terra; FASE - Federação de Órgãos para Assistência Social e Educacional. Os custos ambientais e humanos do negócio de terras: o caso do MATOPIBA. Rio de Janeiro: FASE, 2018.

Fiebrig, I.; Bombardi, L.; Nepomuceno, P. Hypothesising on the emergence of SARS-CoV-2 through bats: its relation to intensive pig-factory farming and the agro-industrial complex. Disponível em: <https://www.researchgate.net/ publication/341525356_Hypothesising_on_the_emergence_of_SARS-CoV-2_through_bats_Its_relation_to_intensive_pig-factory_farming_and_the_agro-industrial_complex>. Acesso em: set. 2020.

Folgado, C.A.R. (Org.). Direito e agrotóxico: reflexões sobre o sistema normativo. Rio de Janeiro: Ed Lumen Juris, 2017.

Graziano da Silva, J. Já existem mais obesos que famintos. Valor Econômico, 16 de julho de 2019. Disponível em: $<$ https://valor.globo.com/opiniao/coluna/ja-existem-mais-obesos-que-famintos.ghtml>. Acesso em: ago. 2020.

Gurgel, A. M.; Santos, M. O. S.; Gurgel, I. G. D. Saúde no campo e agrotóxicos: vulnerabilidades socioambientais, político-institucionais e teórico-metodológicas. Recife: Ed UFPE, 2019.

Gurian-Sherman, D. Failure to yield: evaluating the performance of Genetically Engineered Crops, 2009. Disponível em: <https://www.ucsusa.org/resources/failure-yield-evaluating-performance-genetically-engineered-crops $>$. Acesso em: ago. 2020.

Hallmann, C. A.; Sorg, M.; Jongejans, E.; Siepel, H.; Hofland, N.; Schwan, H.; Stenmans, W.; Müller, A.; Sumser, H.; Hörren, T.; Goulson, D.; Kroon, H. More than 75 percent decline over 27 years in total flying insect biomass in protected areas. PLOS ONE, 12(10), e0185809, 2017. doi: 10.1371/journal.pone.0185809

Hilbeck, A.; Binimelis, R.; Defarge, N.; Steinbrecher, R.; Székács, A.; Wickson, F.; Antoniou, M.; Bereano, P. L.; Clark, E. A.; Hansen, M.; Novotny, E.; Heinemann, J.; Meyer, H.; Shiva, V.; Wynne, B. No scientific consensus on GMO safety. Environmental Sciences Europe, 27(4), 2015. doi: 10.1186/s12302-014-0034-1 
IAASTD - International Assessment of Agricultural Knowledge, Science and Technology for Development. Executive Summary of the Synthesis Report. Johannesburg: IAASTD, 2008. Disponível em: <https://www.globalagriculture.org/ fileadmin/files/weltagrarbericht/IAASTDBerichte/IAASTDExecutiveSummarySynthesisReport.pdf $>$. Acesso em: set. 2020.

IAASTD - International Assessment of Agricultural Knowledge, Science and Technology for Development. Agriculture at a Crossroads: IAASTD findings and recommendations for future farming. Berlin: IAASTD, 2016. Disponível em: <https://www.globalagriculture.org/fileadmin/files/ weltagrarbericht/EnglishBrochure/BrochureIAASTD_en_ web_small.pdf $>$. Acesso em: set. 2020.

ISAAA - International Service for the Acquisition of Agri-biotech Applications. ISAAA in 2018: accomplishment report. Ithaca: ISAAA, 2018. Disponível em: <http://www. isaaa.org/resources/publications/annualreport/2018/pdf/ ISAAA-Accomplishment_Report-2018.pdf > . Acesso em: set 2020 .

Johnson, C. K.; Hitchens, P. L.; Pandit, P. S.; Rushmore, J.; Evans, T. S.; Young, C. C. W.; Doyle, M. M. Global shifts in mammalian population trends reveal key predictors of virus spillover risk. Proceedings of the Royal Society B, 287(1924), 2020. doi: 10.1098/rspb.2019.2736

Korybko, A. Guerras híbridas: das revoluções coloridas aos golpes. São Paulo: Expressão Popular, 2018.

Lara, S. S.; Pignati, W. A.; Pignatti, M. G.; Leão, L. H. C.; Machado, J. M. H. A agricultura do agronegócio e sua relaçâo com a intoxicação aguda por agrotóxicos no Brasil. Hygeia, 15(32), 1-19, 2019. doi: 10.14393/Hygeia153246822

Leite, A. Z.; Castro, L. F. P.; Sauer, S. A questão agrária no momento político brasileiro: liberalização e mercantilização da terra no estado mínimo de Temer. Revista OKARA, 12(2), 247-274, 2018. doi: 10.22478/ufpb. 1982-3878.2018v12n2.41316

Leite, A. Z.; Tubino, N. L. G.; Sauer, S. Políticas públicas para terra e território: um olhar prospectivo sobre os próximos quatro anos no campo brasileiro. In: Azevedo, J. S. G. de; Pochmann, M. (Orgs.). Brasil incertezas e submissão?. São Paulo: Perseu Abramo, p. 171-189, 2019.
Mattis, J.; Hoffman, H. Future Warfare: the rise of hybrid wars. Proceedings Magazine, 131(11), 2005. Disponível em: <https://www.usni.org/magazines/proceedings/2005/ november/future-warfare-rise-hybrid-wars $>$. Acesso em: ago. 2020.

MAPA - Ministério da Agricultura, Pecuária e Abastecimento. Projeções do agronegócio: Brasil 2018/19 a 2028/29: projeções de longo prazo. Brasília: Mapa, 2019.

Mapbiomas. Coleção 4.0 da Série Anual de Mapas de Cobertura e Uso de Solo do Brasil. 2019. Disponível em: $<$ https://mapbiomas.org/>. Acesso em: ago. 2020.

Martins, A. F. G. A produção Ecológica de Arroz e a Reforma Agrária Popular. São Paulo: Expressão Popular, 2019.

McKay, B. M. Agrarian Extractivism in Bolivia. World Development, 97, 199-211, 2017. doi: 10.1016/j.worlddev.2017.04.007

McKittrick, K. Plantation futures. Small axe, 17(3(42)), 1-15, 2013. doi: 10.1215/07990537-2378892

Melgarejo, L. Biosafety regulations, practices and consequences in Brazil: who wants to hide the problems? In: Issberner, L-R; Léna, P. (Eds.). Brazil in the anthropocene: conflicts between predatory development and environmental policies. New York: Routledge, p. 143-157, 2018.

Mpofu, E. COVID-19 crisis: time to reflect on how we live and interact with nature. Agriculture and Human Values, 37, 541-542, 2020. doi: 10.1007/s10460-020-10046-4

Myhr, A.; Traavick, T. The precautionary principle: scientific uncertainty and omitted research in the context of GMO use release. Journal of Agricultural and Environmental Ethics, 15, 73-86, 2002. doi: 10.1023/A:1013814108502

Naeem, S.; Duffy, J. E.; Zavaleta, E. The Functions of Biological Diversity in an Age of Extinction. Science, 336(6087), 1401-1406, 2012. doi: 10.1126/science.1215855

Papa Francisco. Carta encíclica Laudato Si': sobre o cuidado da Casa Comum. São Paulo: Ed. Paulinas, 2015.

Pinheiro Machado, L. C.; Pinheiro Machado Filho, L. C. A dialética da Agroecologia: contribuição para um mundo com alimentos sem veneno. São Paulo: Ed. Expressão Popular, 2014. 
Ploeg, J. D. van der. From biomedical to politico-economic crisis: the food system in times of Covid-19. The Journal of Peasant Studies, 47(5), 944-972, 2020. doi: 10.1080/03066150.2020.1794843

PNUMA - Programa de las Naciones Unidas para el Medio Ambiente. Fronteras 2017: nuevos temas de interés ambiental. Nairobi: Programa de las Naciones Unidas para el Medio Ambiente, 2017.

Pompeia, C. "Agro é tudo": simulações no aparato de legitimação do agronegócio. Horizontes antropológicos, 26(56), 195-224, 2020. doi: 10.1590/S0104-71832020000100009

Ribeiro, S. Novos transgênicos: alertas sobre câncer e toxicidade. Brasil de Fato, 08 de agosto de 2018. Disponível em: <https://www.brasildefato.com.br/2018/08/08/artigo-or-novos-transgenicos-alertas-sobre-cancer-e-toxicidade/>. Acesso em: ago. 2020.

Sánchez-Bayo, F.; Wyckhuys, K. A. G. Worldwide decline of the entomofauna: A review of its drivers. Biological Conservation 232, 8-27, 2019. doi: 10.1016/j.biocon.2019.01.020

Santos, M.; Glass, V. Atlas do Agronegócio: fatos e números sobre as corporações que controlam o que comemos. Rio de Janeiro: Fundação Heinrich Böll, 2018. Disponível em: $<$ https://br.boell.org/sites/default/files/atlas_agro_final_06-09. pdf $>$. Acesso em: set. 2020.

Sassen, S. Expulsões: brutalidade e complexidade na economia global. Rio de Janeiro: Paz \& Terra, 2016.

Sauer, S.; Leite, A. Z. Medida Provisória 759: descaminhos da reforma agrária e legalização da grilagem de terras no Brasil. Retratos de Assentamentos, 20(1), 14-40, 2017. doi: 10.25059/2527-2594/retratosdeassentamentos/2017. v20i1.258

Sauer, S.; Leite, A. Z.; Tubino, N. L. G. Agenda política da terra no governo Bolsonaro. Revista ANPEGE, 16(29), 283-316, 2020. doi: 10.5418/ra2020.v16i29.12518

Sauer, S.; Leite, S. P. Expansão agrícola, preços e apropriação de terra por estrangeiros no Brasil. Revista de Economia e Sociologia Rural, 50(3), 503-524, 2012.

doi: 10.1590/S0103-20032012000300007

Shiva, V. Monoculturas da mente: perspectiva da biodiver- sidade e da biotecnologia. São Paulo: Gala, 2003.

Shiva, V.; Anilkumar, P.; Ahluwalia, U. Ag One: recolonisation of agriculture. New Delhi: Navdanya/RFSTE, 2020. Disponível em: <http://www.navdanya.org/site/ attachments/article/703/Ag-One-17thfeb.pdf $>$. Acesso em: set. 2020 .

Souza, M. M. O. de; Folgado, C. A. R. (Orgs.). Agrotóxicos e agroecologia: enfrentamentos científicos, jurídicos e socioambientais. Anápolis: Editora UEG, 2019.

Swinburn, B. A.; Kraak, V. I.; Allender, S.; Atkins, V. J.; Baker, P. I.; Bogard, J. R.; Brinsden, H.; Calvillo, A.; Schutter, O. D.; R. Devarajan, R; Ezzati, M.; Friel, S.; Goenka, S.; Hammond, R. A.; Hastings, G.; Hawkes, C.; Herrero, M.; Hovmand, P. S.; Howden, M.; Jaacks, L. M.; Kapetanaki, A. B.; Kasman, M.; Kuhnlein, H. V.; Kumanyika, S. K.; Larijani, B.; Lobstein, T.; Long, M. W.; Matsudo, V. K. R.; Mills, S. D. H.; Morgan, G.; Morshed, A.; Nece, P. M.; Pan, A.; Patterson, D. W.; Sacks, G.; Shekar, M.; Simmons, G. L.; Smit, W.; Tootee, A.; Vandevijvere, S.; Waterlander, W. E.; Wolfenden, L.; Dietz, W. H. The Global Syndemic of Obesity, Undernutrition, and Climate Change: The Lancet Commission report. The Lancet Commissions, 393(10173), 791-846, 2019. doi: 10.1016/S0140-6736(18)32822-8

Tabashnik, B. E.; Brévault, T.; Carrière, Y. Insect resistance to Bt crops: lessons for the first billion acres. Nature Biotechnology, 31, 510-521, 2013. doi: 10.1038/nbt.2597

Toledo, V.; Barrera-Bassols, N. Memória biocultural: a importância ecológica das sabedorias tradicionais. São Paulo: Expressão Popular, 2015.

UNCTAD - United Nations Conference on Trade and Development. Trade and environment review 2013: make agriculture truly sustainable now for food security in a changing climate: wake up before it is too late. Geneve: UNCTAD, 2013. Disponível em: <https://unctad.org/en/ PublicationsLibrary/ditcted2012d3_en.pdf $>$. Acesso em: ago. 2020.

UNEP - United Nations Environment Programme. UNEP Frontiers 2016 Report: emerging issues of environmental concern. Nairobi: UNEP, 2016. Disponível em:

$<$ https://wedocs.unep.org/bitstream/handle/20.500.11822/7664/Frontiers_2016.pdf $>$. Acesso em: 
ago. 2020.

UNEP - United Nations Environment Programme; ILRI International Livestock Research Institute. Preventing the Next Pandemic: zoonotic diseases and how to break the chain of transmission. Nairobi: United Nations Environment Programme, 2020. Disponível em: $<$ https://wedocs.unep. $\mathrm{org} / \mathrm{bitstream} /$ handle/20.500.11822/32316/ZP.pdf $>$. Acesso em: ago. 2020.

WEF - World Economic Forum. The Global Risks Report 2020. 15 ed. Geneve, WEF, 2020a.

WEF - World Economic Forum. New Nature Economy Report II: the future of nature and business. Geneve, WEF, 2020b.
Weitz, J. S.; Beckett, S. J.; Coenen, A. R.; Demory, D.; Dominguez-Mirazo, M.; Dushoff, J.; Chung-Yin, L.; Li, G.; Măgălie, A.; Park, S. W.; Rodriguez-Gonzalez, R.;

Zanoni, M.; Melgarejo, L.; Nodari, R.; Dal'Soglio, F. K.; Kageyama, P. Y.; Ferraz, J. M.; Brack, P; Silva, S. T. da; Chomenko, L. E.; Defune, G. O. Biorrisco e a Comissão Nacional de Biossegurança: lições de uma experiência. In: Zanoni, M.; Ferment, G. (Orgs.). Transgênicos para quem?: agricultura, ciência e sociedade. Brasília: MDA, p. 250-282, 2011.

Zanoni, M.; Ferment, G. (Orgs.). Transgênicos para quem?: agricultura, ciência e sociedade. Brasília: MDA, 2011. 